OPEN ACCESS

Edited by:

Elisa R. Zanier,

Mario Negri Pharmacological

Research Institute (IRCCS), Italy

Reviewed by:

Bruce G. Lyeth,

University of California, Davis,

United States

Tiffany Greco,

University of California, Los Angeles,

United States

*Correspondence:

Ramesh Raghupathi

rr79@drexel.edu

Specialty section:

This article was submitted to

Neurotrauma,

a section of the journal

Frontiers in Neurology

Received: 18 September 2020 Accepted: 10 November 2020 Published: 02 December 2020

Citation:

Lengel D, Sevilla C, Romm ZL, Huh JW and Raghupathi R (2020)

Stem Cell Therapy for Pediatric

Traumatic Brain Injury.

Front. Neurol. 11:601286

doi: 10.3389/fneur.2020.601286

\section{Stem Cell Therapy for Pediatric Traumatic Brain Injury}

\author{
Dana Lengel ${ }^{1}$, Cruz Sevilla ${ }^{2}$, Zoe L. Romm ${ }^{2}$, Jimmy W. Huh ${ }^{3}$ and Ramesh Raghupathi ${ }^{1,2 \star}$ \\ ${ }^{1}$ Graduate Program in Neuroscience, Drexel University College of Medicine, Philadelphia, PA, United States, ${ }^{2}$ Department of \\ Neurobiology and Anatomy, Drexel University College of Medicine, Philadelphia, PA, United States, ${ }^{3}$ Department of \\ Anesthesiology and Critical Care, Children's Hospital of Philadelphia, Philadelphia, PA, United States
}

There has been a growing interest in the potential of stem cell transplantation as therapy for pediatric brain injuries. Studies in pre-clinical models of pediatric brain injury such as Traumatic Brain Injury (TBI) and neonatal hypoxia-ischemia $(\mathrm{HI})$ have contributed to our understanding of the roles of endogenous stem cells in repair processes and functional recovery following brain injury, and the effects of exogenous stem cell transplantation on recovery from brain injury. Although only a handful of studies have evaluated these effects in models of pediatric TBI, many studies have evaluated stem cell transplantation therapy in models of neonatal $\mathrm{HI}$ which has a considerable overlap of injury pathology with pediatric TBI. In this review, we have summarized data on the effects of stem cell treatments on histopathological and functional outcomes in models of pediatric brain injury. Importantly, we have outlined evidence supporting the potential for stem cell transplantation to mitigate pathology of pediatric TBI including neuroinflammation and white matter injury, and challenges that will need to be addressed to incorporate these therapies to improve functional outcomes following pediatric TBI.

Keywords: pediatric TBI, stem cells, progenitor cells, transplantation, behavior, white matter injury

\section{INTRODUCTION}

Traumatic brain injury (TBI) is the leading cause of death and disability among the pediatric population. In the United States, TBI affects half a million children under the age of 14 years old each year (1-4). Advancement in acute neurosurgical interventions and neurocritical care have led to a decrease in mortality rates over the past decade (5). However, there are a lack of targeted therapies to limit the life-long cognitive, psychosocial, and emotional deficits seen in pediatric TBI patients (5-7). Preclinical studies utilizing stem cell transplantation therapies have shown efficacy in mitigating brain injury pathology in various models of adult TBI and more recently, pediatric brain injuries. This review summarizes what has been learned about the effects of endogenously expressed and exogenously administered stem cells on recovery from pediatric brain injury, and remaining obstacles that need to be resolved in order to improve the safety and efficacy of stem cell therapy in survivors of pediatric TBI.

\section{Behavioral Deficits Following Pediatric TBI}

Traumatic brain injury sustained during childhood can result in long-term visuomotor, cognitive, and behavioral symptoms that cause lifelong disability and impaired quality of life for survivors of childhood TBI. Pediatric TBI patients commonly exhibit impairments in visual perception, gross, and fine motor function (8-11), which can persist for several years following injury $(9,11)$. Pediatric TBI patients also exhibit reduced global intellectual functioning, attention, and processing speed 
which can lead to deficits in learning and acquiring new information (12-15). Up to fifty- percent of children who sustained a TBI were found to have reduced intellectual ability, memory problems, and lower academic achievement relative to healthy peers $(12,16)$. Impairments in executive functions such as processing speed and inhibitory control and reduced adaptive functioning can persist up to 7-10 years post-injury $(12,14,17$, 18). Brain-injured children and adolescents are at heightened risk of impairments in socialization and communication $(9,15)$ and are more likely to exhibit new-onset psychological disorders such as anxiety and mood disorders, post-traumatic stress disorder, and antisocial behavior relative to typically developed school-age children (19-25).

Pediatric TBI has been studied using a variety of preclinical models, including controlled cortical impact (CCI), fluidpercussion injury (FPI), closed-head injury (CHI), weight-drop injury, and rotational injury in rodents of ages ranging from postnatal day 7-28 (26-33). Experimental TBI often results in sensorimotor impairments, typically characterized by decreased duration in a rotarod test $(28,29,33)$ and/or decreased locomotor activity in an open field test (29), resembling the visuomotor impairments observed in pediatric TBI patients. Hippocampal-based learning and memory deficits are also common following brain injury in immature animals (28-32, $34)$. These cognitive deficits are often present at chronic timepoints post-injury $(31,32)$ validating the concept that brain injury in infancy results in the children "growing into the learning and memory deficits." Although the emotional and psychosocial consequences of pediatric TBI have historically received less attention in animal studies relative to cognitive outcomes, a few recent studies have investigated these outcomes after pediatric brain injury. Increased anxiety-like behavior in the elevated plus maze was reported 3 weeks following contusive head trauma in 7-day-old rats (35), and 4 weeks after rotational TBI in 12-day-old mice (33). Deficits in social behavior were reported in adulthood following TBI in 21-day-old mice (36). Preclinical studies of pediatric TBI have begun to place more emphasis on developing a variety of cognitive and psychological tests to measure deficits in brain-injured animals as they age into adolescence and adulthood.

\section{Pathologic Alterations Following Pediatric TBI}

The major pathologic hallmarks of TBI in infants and children include cerebral edema, extra-axial and intraparenchymal hemorrhage, ventriculomegaly, and diffuse axonal injury (DAI) (37). Reductions in cortical, hippocampal and thalamic tissue volume is often observed in neuroimaging studies following TBI in children and correlated with deficits in cognitive function (38-40). Post-traumatic inflammation is thought to be a significant contributor to histopathology following pediatric brain injury (41). Pediatric TBI patients also exhibit elevated levels of proinflammatory cytokines in the cerebrospinal fluid (CSF) in the first 3 days after brain injury, particularly in cases of severe
TBI (42, 43). Together, these observations underscore the complicated nature of the cellular and tissue pathology in brain-injured children.

Preclinical TBI studies have demonstrated diffuse damage in white matter tracts $(27,31,44)$, brain edema (27), ventriculomegaly (31), subarachnoid hemorrhage (27), inflammation $(27,30,33)$, and regional reductions in tissue volume $(30,31)$, resembling the pathology typically observed in patients. Evidence of axonal injury is commonly observed following brain trauma $(27,31)$, in addition to reductions in myelination volume in the corpus callosum (45), resulting in functional white matter deficits. Deficits in compound action potential (CAP) of myelinated fibers in the corpus callosum at $24 \mathrm{~h}$ persisting to at least 2 weeks following closed head injury in the 17-day-old rat have been reported (46). Moreover, contusive injury in 16-18-day old rats resulted in an impairment in the ability to induce long term potentiation in the contralateral somatosensory cortex by stimulating the corpus callosum 2-3 weeks post-injury (44). Observations from both clinical and preclinical studies suggest that the hippocampus is particularly vulnerable to injury-induced pathological changes. Preclinical studies have demonstrated decreased tissue volume (26) in addition to apoptotic cell death (32), neurodegeneration $(34,47)$, and reactive astrocytosis $(27,30)$ within the hippocampal formation. Contusive trauma in 17-day-old rats resulted in decreased dendritic length and branching in the CA1 area of the hippocampus in the injured hemisphere (48). Although less extensively studied in pediatric relative to adult TBI, deficits in hippocampal long-term potentiation (LTP) were reported in both the dentate gyrus and CA1 area of the hippocampus between 1 and 4 weeks after weight-drop injury in juvenile rats (49). Impairment in LTP induction in the dentate gyrus was sustained over a longer period following injury in female rats compared with their male counterparts, whereas impairment in LTP induction in the CA1 area was observed only in male rats (49).

Activation of inflammatory sequelae in both the acute and chronic post-injury phases occur following TBI in immature animals. Concentrations of pro-inflammatory cytokines, including interleukin-1 $\beta$, interleukin-6, and tumor necrosis factor-alpha $(\mathrm{TNF}-\alpha)$ are acutely and rapidly elevated in the injured brain (30) and can remain elevated for several days post-injury (33). Brain regions which are particularly vulnerable to post-traumatic inflammation and microglial activation include the peri-injury region of the cortex, corpus callosum, thalamus, and hippocampus $(27,34)$, which are thought to contribute to sustained cognitive deficits observed following pediatric TBI. Although activation of neuroinflammation can be detrimental following injury to the developing brain, post-injury inflammatory response in the acute post-traumatic period has been suggested to be beneficial for the clearance of cellular debris (50). Collectively, these data provide evidence of the multiple cellular processes that can be targeted for treatment strategies for pediatric TBI particularly in the chronic post-traumatic period. 


\section{EFFECTS OF PEDIATRIC TBI ON ENDOGENOUS STEM CELL POPULATIONS}

Preclinical evidence suggests that injury to the immature brain has robust effects on the proliferation of endogenous stem cell populations [reviewed in Niimi and Levison (51)]. Multiple studies have sought to identify and characterize the distinct stem cell populations that are affected following brain injury which may be a critical factor in developing therapeutic strategies to replenish cells that are lost following brain injury and to enhance the inherent proliferative capabilities of stem cells following pediatric TBI. The location, type, and population density of neural stem cells (NSCs) are developmentally regulated and characterizing the responses of NSCs and neural progenitors (NPs) in the immature brain to injury can aid in the understanding of brain injury pathology and the development of therapeutic targets for pediatric TBI $(51,52)$.

\section{Neural Stem Cells}

The response of neural stem cells (NSCs) to neonatal HI is complex. In the early post-injury phase, increased mitotic activity in the subventricular zone (SVZ) is observed (53-55). However, not all cells within this proliferative zone respond to $\mathrm{HI}$ similarly as the oligodendrocyte progenitors undergo apoptotic cell death (56); resulting in extensive cell death within the SVZ during the first $24-48 \mathrm{~h}$ (56). Although NSCs and glial-restricted progenitor cells survive the injury, PSA-NCAM+ cells (stem cells) as well as late-stage oligodendrocyte progenitors (OPCs) were vulnerable (57-60).

Contusive TBI to the immature brain also found evidence of robust proliferation in response to injury $(52,61)$. In the immature rat, contusive trauma resulted in an increase in the number of neurospheres, an increase in frequency of NSCs and an accelerated growth rate (52). More recently, Zhang et al. (61) reported decreased survival rates of adult-born neurons along with an increase in ectopic migration of adult neurons in the hippocampus following neonatal brain trauma in rabbits. Additional efforts must be directed to better characterizing the effects of TBI on regional responses of the NSCs and NPs.

Despite the robust proliferative response of NSCs and NPs to pediatric brain injury, evidence suggests that most of the newly generated cells do not survive past 1-2 months (52), or predominantly become interneurons or astrocytes rather than mature neurons (62). A significant increase in proliferating glial fibrillary acidic protein (GFAP)-positive cells occurs after both neonatal $\mathrm{HI}$ and pediatric TBI, indicating increased astrocytic proliferation and astrogliosis (62). A few studies have also reported an increase in the number of newly generated oligodendrocytes that presumably originated within the SVZ following HI (63-65). Despite evidence for increased production of oligodenderocytes, impaired myelin production, and axonal loss in the subcortical white matter persist following pediatric brain injury, suggesting that there may be a deficit in the maturation of these newly generated oligodendrocytes (51). In part, this deficit may be driven by increased astrocyte proliferation and associated production of toxic substances that are known to inhibit oligodendrocyte differentiation and the maturation of oligodendrocyte progenitors such as chondroitin sulfate proteoglycans (66). Thus, finding new mechanisms to enhance the long-term survival of newly generated neurons and oliogodendrocyte will be critical for advancing stem-cell based therapies to treat pediatric TBI.

\section{Peripheral Stem Cells}

The bone marrow niche is home to hematopoietic stem cells (HSCs) which are responsive to pediatric brain injuries and play a role in stem cell proliferation, mobilization, and migration. Several studies have found that neonatal HI mobilizes mesenchymal stromal cells (MSCs) in the peripheral blood which migrate to the location of the injured tissue where they can potentially aid in tissue repair and regeneration (67-69). In part, this mobilization and recruitment may be mediated by the actions of stromal cell-derived factor 1 (SDF1) (70) or stem cell factor (SCF) both of which increase in expression within the hippocampus, corpus callosum, and periventricular areas between 3 and 7 days following neonatal HI $(69,71-73)$.

\section{STEM CELL TRANSPLANTATION IN PEDIATRIC TBI}

A growing body of literature has accumulated supporting the potential of NSCs (either embryonic or adult) and/or MSCs (from either the bone marrow or umbilical cord) to treat the pathophysiology of TBI [reviewed by Mashkouri et al. (68)]. The self-renewal ability of NSCs and inherent potential to differentiate into neurons and glial cells provides the potential to promote regeneration and neurogenesis in the injured brain (74), while MSCs are advantageous due to their ability to cross the blood brain barrier (BBB), migrate to the site of injury, and secrete anti-inflammatory and trophic factors that protect against cell death (67). These approaches have demonstrated that stem cell therapy is effective in mitigating neuronal cell death and inflammatory cascades following TBI, resulting in improved recovery of cognitive and motor functions $(67,68,74)$. Although these strategies have been employed in models of adult TBI, there is a growing body of literature supporting similar beneficial effects of stem cell treatments using models of pediatric brain injury. For example, stem cells derived from umbilical cord blood were found to mitigate neurovascular injury following neonatal brain injury (75). Evaluating the effects of stem cell therapies in these neonatal brain injury models will provide important guidance for directing future research on developing targeted and effective stem cell treatments for pediatric TBI.

\section{Survival of Cells}

Evidence from adult animals suggests that cells grafted in the hostile environment of the injured brain often exhibit poor survival $(76,77)$. In the interest of improving the translational value of using stem/progenitor cells, systemic routes have been tested for efficacy of cell therapy although intravenously administered stem cells can become localized in peripheral organs (such as the lungs or the spleen) rather than migrating to the brain (78). Limited evidence from pediatric animal studies suggests that NSCs can survive and differentiate into neurons, 
astrocytes, and oligodendrocytes in the injured brain. Long-term survival and differentiation of implanted NSCs was observed 4-5 weeks after intraventricular (79) or intranasal (80) following HI in neonatal mice. Differentiated NSCs were observed up to 2 months after transplantation into the CA3 area of the hippocampus 2 weeks following global ischemia in adolescent rats (81). Intravenously administered MSCs were only observed in the contralesional hemisphere following $\mathrm{HI}$ in 1-week-old rats, while beneficial effects of MSC treatment on recovery of motor function, brain volume, cortical thickness, and neuronal density were observed (82). Intranasal administration of stem cells has become an attractive and minimally invasive method to deliver cells into the injured brain that has shown efficacy in preclinical studies of neonatal HI $(80,83,84)$ and will likely be more commonly utilized in future research.

\section{Histopathology and Inflammation}

Although enhancing the long-term survival and integration remains an important goal of stem cell therapy, accumulating evidence has highlighted the importance of trophic support and/or anti-inflammatory effects in facilitating the beneficial actions of stem cells in treating the injured brain. NSCs can secrete neurotrophic factors such as nerve growth factor (NGF) and brain-derived neurotrophic factor (BDNF) (85) which promote repair processes and plasticity. MSCs are also known to exert beneficial trophic factors (86-88) as well as anti-inflammatory and antioxidant effects $(57,89,90)$ which can attenuate systemic inflammation, a key aspect of pediatric brain injuries. Based on in vitro studies using co-cultures of glial-restricted precursor cells (GRPs) with neonatal brain slices exposed to oxygen-glucose depravation, GRPs decreased tissue injury and cortical cell death without direct cell-cell contact suggesting that these effects were likely attributable to trophic support provided by the cells (91). Following HI in neonatal rats, administration of NSCs between 1 and 3 days after injury reduced infarct volume $(79,80)$ and decreased the number of apoptotic cells in the hippocampus and cortex (79). The administration of MSCs $24-48 \mathrm{~h}$ following brain injury in neonatal rats significantly reduced cortical neuronal pathology $(92,93)$, and the extent of tissue loss (84). Moreover, MSCadministered groups exhibited an increase in the thickness of the cortex (82) and corpus callosum $(82,94)$ as well as increased neuronal density within the hippocampus (84) compared with vehicle-treated brain-injured animals. MSC administration has also resulted in robust anti-inflammatory effects in models of neonatal HIE. MSC treatment decreased the number of activated microglia in the hippocampus and cortex $(83,84,94)$ and inhibited pro-inflammatory cytokine expression $(92,94,95)$ in addition to increasing anti-inflammatory cytokine expression (92) in the injured brain.

\section{Functional Outcomes}

Efficacy of cell therapy needs to be documented via their effects on behavioral outcomes. Compared with vehicle-treated animals, MSC-administered animals exhibited improved motor function in the rotarod and beam walking tests between 2 and 4 weeks following brain injury $(82,84,92,94)$. Intranasal administration of MSCs 3 days after $\mathrm{HI}$ in neonatal mice also reversed cognitive deficits in the novel object recognition test 5 weeks following injury (83), and MSCs administered into the injured hemisphere $24 \mathrm{~h}$ following $\mathrm{HI}$ in neonatal rats improved spatial learning at 4 weeks following injury (93). Treatment with NSCs similarly improved spatial learning and memory in addition to motor function 2-6 months following brain injury (79-81). MSC administration reversed risk-taking behavior observed in vehicle-treated injured animals in the elevated plus maze 5 weeks following HI in 9-day-old mice (83). One study found that transplantation of hypoxia-preconditioned NPs increased social interaction, sociability, and social recognition following contusive TBI, which was associated with increased expression of oxytocin and oxytocin receptor compared with vehicle-treated animals (96) suggesting that stem cell treatments may also improve psychosocial outcomes after pediatric brain injury.

\section{White Matter Injury}

Bone-marrow derived MSCs (BM-MSCs) administered following adult TBI or neonatal HI demonstrate beneficial effects on white matter repair and regeneration (95, 97-99). Intravenously administered BM-MSCs following contusive TBI in adult rats promoted structural recovery of white matter indicated by increased fractional anisotropy and axonal water fraction analyzed with diffusional kurtosis imaging (98). MSCs may also be beneficial in mitigating white matter injury following $\mathrm{HI}$ presumably by playing a supportive role in oligodendrocyte development (100). Administration of MSCs following neonatal $\mathrm{HI}$ increased myelination and expression of myelin basic protein $(\operatorname{MBP})(95,97,99)$, reduced microglia and astrocyte activity (99), and decreased pro-inflammatory cytokine expression (95). Thus, stem cell treatments utilizing MSCs would likely be similarly beneficial for mitigating neuroinflammation and diffuse axonal injury following pediatric TBI.

\section{Neurovascular Injury}

Stem cells derived from umbilical cord blood demonstrate great therapeutic potential due to their ability to mitigate damage to the neurovascular unit following brain injury $(75,101)$. Treatment with umbilical cord-derived endothelial progenitor cells (EPCs) following $\mathrm{HI}$ in 7-day-old rats decreased bloodbrain barrier damage, brain tissue loss, and deficits in motor function (101). Injured animals infused with umbilical-vein derived EPCs exhibited less apoptosis in the cortex $24 \mathrm{~h}$ following injury, which was associated with increased expression of stromal cell-derived factor 1 (102). Transplantation of umbilical cord blood CD34+ cells 1 week following $\mathrm{HI}$ in 7-day-old rats improved motor function and decreased the expression of GFAP and apoptotic genes in the injured brain (103). Although EPCs are potentially neuroprotective by facilitating angiogenesis and neovascularization, they may increase BBB permeabilitypresumably via increasing the local concentration of vascular endothelial growth factor, further exposing the brain to systemic toxins and inflammatory mediators $(75,104)$. 


\section{Combinatorial Treatments Utilizing Stem Cells}

The effectiveness of stem cell treatment combined with other pharmacotherapies in preclinical models of TBI is currently being established. These combination therapies may exhibit synergistic effects and result in greater neuroprotection relative to stem cell or pharmacological monotherapy $(79,105)$. Moreover, some combination therapies may enhance the viability and survival of implanted stem cells in the injured brain $(76,79)$.

\section{Anti-inflammatory Agents}

Anti-inflammatory therapies such as minocycline show promise in adult TBI studies (68), although excessive doses have resulted in worse outcomes, highlighting the importance of the acute inflammatory response to brain injury. Nonetheless, combined treatment with BM-MSCs and minocycline $24 \mathrm{~h}$ following cerebral ischemic injury in adult rats resulted in the most histological and functional improvement compared to treatment with MSCs or minocycline alone, including reduction in cell degeneration and increased neuronal density within the hippocampus (106). However, we have previously demonstrated that acute minocycline treatment following closed-head-injury in the neonate rat may exacerbate neurodegeneration and cognitive deficits $(47,107)$, suggesting that age-at-injury is an important consideration for developing combination stem cell treatments in pediatric TBI.

\section{Granulocyte-Colony Stimulating Factor (G-CSF)}

Another promising candidate for treatment of TBI is granulocyte-colony stimulating factor (G-CSF), which has an inherent capability to reduce brain edema and promote functional recovery following TBI. G-CSF also promotes neuroprotection of implanted stem cells (108) and recruitment of endogenous stem cells within the bone marrow into the blood stream where they can migrate to the injured brain (68). Combined treatment with umbilical cord blood cells and G-CSF exhibited synergistic effects on inflammation, neurogenesis, and hippocampal cell loss, in addition to more robust and long-term functional recovery following CCI in adult rats (105). Following $\mathrm{HI}$ in neonatal rats, treatment with G-CSF decreased apoptotic cell death (109), enhanced neurogenesis and improved cognitive function (110). Although the effects of G-CSF in combination with stem cell treatment have not been evaluated in pediatric studies, combined treatment with G-CSF and stem cell factor following HIE in 7-day-old rats exhibited similar synergistic effects, resulting in decreased brain tissue atrophy and improved motor function (111). Thus, combined treatment with G-CSF and stem cells would likely have beneficial effects in pediatric HIE and TBI and should be explored further.

\section{Mild Hypothermia}

Mild hypothermia (HT) is currently the only therapy approved for the treatment of neonatal HI. Mild HT usually involves cooling the body to $32-35$ degrees Celsius for $12-72 \mathrm{~h}$ within the first $6 \mathrm{~h}$ after HI (112). In clinical settings, mild HT has been shown to decrease morbidity and mortality in infants exposed to HI, although many infants still suffer from brain damage and disability even with HT treatment (112). In preclinical studies, HT reduced apoptotic cell death, infarct volume, and improved functional outcomes following HI $(79,83)$. Preclinical studies have begun to evaluate the effects of combined treatment with hypothermia and stem cells in neonatal HI. Mild HT combined with NSC transplantation $24 \mathrm{~h}$ following HI in 1-weekold mice resulted in a greater reduction in apoptotic cells in the hippocampus and cortex, smaller infarct volume, and improved neurological function compared to either treatment alone (79). Moreover, HT-NSC treated mice exhibited greater survival and differentiation of NSCs into mature neurons (79), suggesting that hypothermia treatment may increase the survival and longterm integration of NSCs in the injured brain. Compared with rats treated with HT or MSCs alone, HT combined with MSC treatment following $\mathrm{HI}$ in 7-day-old rats exhibited the greatest improvement in cell death, gliosis, inflammation, and motor function (113). However, a more recent study reported worse outcomes when HT (delivered at $4 \mathrm{~h}$ after injury) was combined with delayed treatment with MSCs, delivered intranasally 3 days following $\mathrm{HI}$ injury in neonatal mice (83). While both HT and MSC treatment alone prevented reductions in myelin basic protein (MBP) expression and neuronal density within the hippocampus and striatum, these effects were attenuated when the treatments were combined (83). Injured mice exhibited cognitive deficits in the novel object recognition test that were reversed by MSC treatment alone, but not by HT or combined treatment (83). Thus, further evaluation of the effects of stem cell treatment and HT will be required in order to develop an effective combination therapy to treat pediatric brain injury.

\section{Hypoxic Preconditioning of Implanted Stem Cells}

Interestingly, there is recent evidence to suggest that hypoxic preconditioning could increase the therapeutic potential of stem cells $(96,114,115)$ and may enhance the regenerative capacity of endogenous NSCs in the SVZ (116). Hypoxic preconditioning followed $24 \mathrm{~h}$ later by $\mathrm{HI}$ in 1-day-old piglets resulted in a significant increase in neurogenesis in the SVZ compared with normoxic controls, which was observed up to 1 week following preconditioning (116). In a murine model of ischemia, hypoxic preconditioning increased the survival and proliferation of transplanted MSCs which was mediated by suppression of apoptotic signaling and facilitation of the secretion of angiogenic factors (114). Thus, hypoxic preconditioning may be one strategy to enhance the survival and proliferative capabilities of implanted cells within the injured host environment.

\section{Modification of Stem Cells to Express Neurotrophic Factors}

Modifying stem cells to overexpress neurotrophic factors such as BDNF could maximize the inherent neurotrophic benefits of stem cell treatments in pediatric brain injuries (117, 118). BDNF promotes neurogenesis and synaptic plasticity, and reductions in BDNF in the injured brain are observed following both TBI and neonatal HIE (84). Recent evidence indicates that BDNF may enhance myelin regeneration after injury through the $\operatorname{TrkB}$ receptor $(119,120)$. In a rodent 
model of CNS demyelination, the TrkB agonist LM22A-4 increased myelin thickness and the density of oligodendrocytes 1 week following injury (120). The effects of treatment with stem cells overexpressing BDNF has been evaluated following neonatal stroke. Intranasal delivery of MSCs alone or MSCs overexpressing BDNF (MSC-BDNF) following neonatal stroke were equally effective in reducing infarct size and white matter injury, and both treatments induced cell proliferation in the injured hemisphere (117). However, injured rats treated with MSC-BDNF exhibited additional improvements in motor function at 2 weeks following injury compared with rats treated with MSCs, although these differences were no longer observed at 4 weeks following injury (117). Similarly, intranasal administration of NSCs or NSCs overexpressing basic fibroblast growth factor (NSC-bFGF) following neonatal HI were similarly effective in reducing infarct volume and improving motor function 3-5 weeks following injury (80). Notably, NSC-bFGF had the added benefit of increasing the number of NSCs that differentiated into neurons within the hippocampus and cortex at 35 days after injury relative to the NSC only treatment group (80), suggesting that neurotrophic factors may help promote that survival and integration of implanted NSCs.

\section{Stem Cell-Derived Exosomes}

A novel therapeutic approach to treat brain injuries has been the use of exosomes derived from stem cells. Exosomes are extracellular vesicles that are produced from the plasma membrane and released into the extracellular space, where they can participate in intracellular signaling through several mechanisms (121). Secreted exosomes can be taken up by other cells via membrane fusion, endocytosis, or ligand-receptor interactions, where their contents can then be released within the target cells (121). In a swine model of TBI, MSCderived exosomes given during the first 2 weeks post-injury decreased the neurological severity score, and brain-injured animals given exosomes exhibited a significantly shorter time to complete neurologic recovery (122). Moreover, MSC-derived exosomes attenuated post-injury inflammation and improved motor function following CCI $(123,124)$. The effects of MSCderived exosomes have also been evaluated in neonatal $\mathrm{HI}$. A combination of $\mathrm{HI}$ and neuroinflammation was induced in 2-3-day old rat pups through lipopolysaccharide injection, followed $2 \mathrm{~h}$ later by HI. Exosomes derived from umbilical cord-derived MSCs were delivered intranasally in between the inflammatory and $\mathrm{HI}$ insults. They observed that the exosome-treated injured group exhibited less expression of inflammatory cytokines and neuronal cell death $24 \mathrm{~h}$ following injury, and improved spatial learning in the Morris water maze 4 weeks following injury $(125,126)$. In a different study, MSC-derived exosomes were delivered via in utero intravenous administration following global $\mathrm{HI}$ in ovine fetuses. In contrast to the previous study, they did not observe an effect of the exosome treatment on post-injury inflammation (127), although exosome treatment reduced seizure activity and hypomyelination in the injured brain 1-week post H-I (127).

\section{SUMMARY}

TBI remains a leading cause of death and disability in infants and children which lacks treatment options to mitigate the debilitating life-long symptoms experienced by survivors. Stem-cell based therapies can take advantage of the robust proliferative capacity and plasticity in the immature brain, and thus have potential to become an effective treatment for pediatric TBI. Although the beneficial effects of exogenous stem cell transplantation have been established in adult TBI and stroke models, additional research is necessary to determine whether these benefits of stem cell therapy translate to pediatric TBI. Treatments for pediatric TBI require unique considerations that may differ from adult TBI due to differences in the spatial and temporal dynamic of the brain injury. Thus, certain challenges and limitations still need to be overcome in order to translate stem cell treatment methods from adult to pediatric TBI. For example, exogenous stem cells are often transplanted directly into the cavity resulting from TBI in the adult brain. However, this approach is less ideal in the pediatric brain where there is less likely to be an overt cavity or lesion. Therefore, systemic administration of cells through intravenous or intranasal methods has been more commonly utilized in models of pediatric brain injury. Intravenous administration is also desirable because it can be easily translated to the clinical setting as a non-invasive method to deliver stem cells.

Developmental differences between the immature and adult brain also complicate the translation of stem cell treatments to pediatric TBI models. For instance, although the neuroinflammatory response is a key aspect of TBI, the localization and function of microglia during early development differs from the adult brain. Previous evidence suggests that the white matter of the human fetus/infant is densely populated with activated (CD-68+) microglia (128). During very early postnatal development, microglia play important roles in white matter development as well as neuronal differentiation and survival, as they are a crucial source of neurotrophins such as NGF and BDNF (129). Thus, while anti-microglial treatments such as minocycline in combination with stem cell therapy have shown beneficial effects in adult TBI (68), depletion of microglia during postnatal development increases the number of apoptotic in the cerebral cortex (129) and exacerbates neurodegeneration after neonate TBI (50).

The immature brain is also particularly vulnerable to enhanced levels of pro-inflammatory cytokines and free radicals produced by microglia after brain injury due to the reduced antioxidant capacity of the developing brain as well as the vulnerability of OPCs within the white matter tracts $(129,130)$. Recent studies utilizing administration of exogenous stem cells have demonstrated numerous beneficial effects on post-injury histological, cognitive, and behavioral outcomes in models of pediatric brain injury. In particular, BM-MSCs and umbilicalcord derived blood cells (UCBC) have shown promising results in preclinical models of neonatal HI through their potent antiinflammatory effects and trophic support. Thus, it is likely that pediatric TBI will be amenable to these stem cell therapies due to overlapping pathologies with neonatal HI. However, 
further investigation of these treatments will be necessary to determine their effectiveness as well as potential risks in models of pediatric TBI.

The effects of stem cell treatments in adolescent models of TBI have not been investigated, although transplantation of NSCs improved functional outcomes following global ischemia in adolescent rats (81). TBI during adolescence has deleterious effects on developmental processes such as synaptogenesis and synaptic pruning that are critical during this period (131-133). For example, TBI in juvenile rats led to increased neuronal complexity and spine density of pyramidal neurons the prefrontal cortex, suggestive of disruption of normal pruning processes (133). These effects may be influenced in part by the aberrant effects of TBI on microglial activation and function (132). Pediatric TBI increases the number of activated microglia in the injured brain $(107,132)$. Moreover, microglia can become chronically activated after TBI, residing in a "primed" state that can further exacerbate inflammatory responses and negatively impact functional outcomes (132). These shifts in microglial morphology toward an activated state can also hinder their normal homeostatic role in CNS development, including microglial-dependent synaptic pruning observed in the thalamus, cerebellum, and hippocampus (132). Aberrant synaptic pruning has been strongly linked to neurological dysfunction and is associated with numerous developmental psychiatric disorders including Schizophrenia and Autism Spectrum Disorder (131, 132). Thus, stem cell treatment may have potential in mitigating neurological and behavioral dysfunction in adolescent TBI due to well-documented anti-inflammatory effects and inhibition of microglial activation following brain injury $(83,84,94)$ which should be explored further.

A promising therapeutic approach that would be well-suited for pediatric TBI patients is to target the survival of endogenous stem cells, as this would take advantage the robust proliferative capacity in the immature brain in response to TBI (52). This approach is also desirable because it can avoid certain limitations associated with transplantation of exogenous cells. One of the main challenges pertaining to the responses of endogenous stem cells is the poor long-term survival and maturation of these cells after brain injury, particularly of NSCs and OPCs (62). Thus, optimizing strategies to increase the retention and integration

\section{REFERENCES}

1. Araki T, Yokota H, Morita A. Pediatric traumatic brain injury: characteristic features, diagnosis, and management. Neurol. Med. Chir. (2017) 57:82-93. doi: 10.2176/nmc.ra.2016-0191

2. Coronado VG, Xu L, Basavaraju SV, McGuire LC, Wald MM, et al. Surveillance for traumatic brain injury-related deaths-United States, 1997-2007. MMWR Surveill. Summ. (2011) 60:1-32. Available online at: https://www.cdc.gov/mmwr/preview/mmwrhtml/ss6005a1.htm

3. Emami P, Czorlich P, Fritzsche FS, Westphal M, Rueger JM, et al. Impact of glasgow coma scale score and pupil parameters on mortality rate and outcome in pediatric and adult severe traumatic brain injury: a retrospective, multicenter cohort study. J. Neurosurg. (2017) 126:760-7. doi: 10.3171/2016.1.JNS152385 of newly generated neurons and oligodendrocytes would be greatly advantageous for treating pediatric TBI. TBI in immature animals and children affects the hypothalamic pituitary adrenalaxis leading to chronically elevated levels of stress hormones (35, 134). Elevated brain concentrations of corticosterone increase cell death in the hippocampus (135) and thus may further contribute to the hostile environment impeding the survival of implanted cells following TBI. Various types of drugs, growth factors, and other signaling molecules can improve neurogenesis and the recovery of cognitive function after TBI $(70,72,73)$. Although the majority of these agents have been limited to adult studies, a number of signaling molecules which regulate stem cell mobilization have been evaluated in the context of pediatric brain injury. Stromal Cell-Derived Factor 1, a mediator of MSC and UCBC mobilization, is upregulated following neonatal HI injury (71, 73). Moreover, intracranial injection of SDF1 decreased inflammation, promoted re-myelination, and improved spatial learning following neonatal HI (70). Similarly, SCF is upregulated in neurons after brain injury and induces the migration of proliferating NSCs to areas of injured tissue (72). Treatment with SCF following HI in 7-day-old rats resulted in decreased brain tissue atrophy and improved motor outcomes (111), suggesting that both SDF1 and SCF would likely be similarly beneficial for the treatment of pediatric TBI. Thus, future research should place more emphasis on developing strategies to target the survival and maturation of endogenous stem cells for the treatment of pediatric TBI.

\section{AUTHOR CONTRIBUTIONS}

All authors listed have made a substantial, direct and intellectual contribution to the work, and approved it for publication.

\section{ACKNOWLEDGMENTS}

These studies were supported, in part, by grants from the National Institutes of Health R01 NS110898 (JH and RR) and Commonwealth Universal Research Enhancement from the Pennsylvania Department of Health SAP 410-007-9710 (RR) and SAP 410-007-7079 (RR).
4. Faul M, Coronado V. Epidemiology of traumatic brain injury. Handb. Clin. Neurol. (2015) 127:3-13. doi: 10.1016/B978-0-444-52892-6.00001-5

5. Huh JW, Raghupathi R. Therapeutic strategies to target acute and long-term sequelae of pediatric traumatic brain injury. Neuropharmacology. (2019) 145:153-9. doi: 10.1016/j.neuropharm.2018.06.025

6. Kochanek PM, Tasker RC, Carney N, Totten AM, Adelson PD, et al. Guidelines for the management of pediatric severe traumatic brain injury, third edition: update of the brain trauma foundation guidelines, executive summary. Neurosurgery. (2019) 84:1169-78. doi: 10.1093/neuros/nyz051

7. Thurman DJ. The epidemiology of traumatic brain injury in children and youths: a review of research since 1990. J. Child Neurol. (2016) 31:20-7. doi: $10.1177 / 0883073814544363$

8. Chaplin D, Deitz J, Jaffe KM. Motor performance in children after traumatic brain injury. Arch. Phys. Med. Rehabil. (1993) 74:161-4. 
9. Fay GC, Jaffe KM, Polissar NL, Liao S, Rivara JB, Martin KM. Outcome of pediatric traumatic brain injury at three years: a cohort study. Arch. Phys. Med. Rehabil. (1994) 75:733-41. doi: 10.1016/0003-9993(94)90127-9

10. Konigs M, Heij HA, van der Sluijs JA, Vermeulen RJ, Goslings JC, et al. Pediatric traumatic brain injury and attention deficit. Pediatrics. (2015) 136:534-41. doi: 10.1542/peds.2015-0437

11. Stephens J, Salorio C, Denckla M, Mostofsky S, Suskauer S. Subtle motor findings during recovery from pediatric traumatic brain injury: a preliminary report. J. Mot. Behav. (2017) 49:20-6. doi: 10.1080/00222895.2016.1204267

12. Anderson V, Catroppa C, Morse S, Haritou F, Rosenfeld J. Recovery of intellectual ability following traumatic brain injury in childhood: impact of injury severity and age at injury. Pediatr. Neurosurg. (2000) 32:282-90. doi: $10.1159 / 000028956$

13. Keenan HT, Clark AE, Holubkov R, Cox CS, Ewing-Cobbs L. Psychosocial and executive function recovery trajectories one year after pediatric traumatic brain injury: the influence of age and injury severity. J. Neurotrauma. (2018) 35:286-96. doi: 10.1089/neu.2017.5265

14. Treble-Barna A, Schultz H, Minich N, Taylor HG, Yeates KO, et al. Longterm classroom functioning and its association with neuropsychological and academic performance following traumatic brain injury during early childhood. Neuropsychology. (2017) 31:486-98. doi: 10.1037/neu0000325

15. Zamani A, Ryan NP, Wright DK, Caeyenberghs K, Semple BD. The impact of traumatic injury to the immature human brain: a scoping review with insights from advanced structural neuroimaging. J. Neurotrauma. (2020) 37:724-38. doi: 10.1089/neu.2019.6895

16. Ewing-Cobbs L, Prasad MR, Kramer L, Cox CSJr, Baumgartner J, et al. Late intellectual and academic outcomes following traumatic brain injury sustained during early childhood. J. Neurosurg. (2006) 105:287-96. doi: 10.3171/ped.2006.105.4.287

17. Catroppa C, Anderson VA, Morse SA, Haritou F, Rosenfeld JV. Outcome and predictors of functional recovery 5 years following pediatric traumatic brain injury (TBI). J. Pediatr. Psychol. (2008) 33:707-18. doi: 10.1093/jpepsy/jsn006

18. Catroppa C, Godfrey C, Rosenfeld JV, Hearps SS, Anderson VA. Functional recovery ten years after pediatric traumatic brain injury: outcomes and predictors. J. Neurotrauma. (2012) 29:2539-47. doi: 10.1089/neu.201 2.2403

19. Kennedy E, Heron J, Munafo M. Substance use, criminal behaviour and psychiatric symptoms following childhood traumatic brain injury: findings from the ALSPAC cohort. Eur. Child Adolesc. Psychiatry. (2017) 26:1197-206. doi: 10.1007/s00787-017-0975-1

20. Luis CA, Mittenberg W. Mood and anxiety disorders following pediatric traumatic brain injury: a prospective study. J. Clin. Exp. Neuropsychol. (2002) 24:270-9. doi: 10.1076/jcen.24.3.270.982

21. Max JE, Pardo D, Hanten G, Schachar RJ, Saunders AE, et al. Psychiatric disorders in children and adolescents six-to-twelve months after mild traumatic brain injury. J. Neuropsychiatry Clin. Neurosci. (2013) 25:272-82. doi: 10.1176/appi.neuropsych.12040078

22. Max JE, Schachar RJ, Landis J, Bigler ED, Wilde EA, et al. Psychiatric disorders in children and adolescents in the first six months after mild traumatic brain injury. J. Neuropsychiatry Clin. Neurosci. (2013) 25:187-97. doi: 10.1176/appi.neuropsych.12010011

23. McKinlay A, Corrigan J, Horwood LJ, Fergusson DM. Substance abuse and criminal activities following traumatic brain injury in childhood, adolescence, and early adulthood. J. Head Trauma Rehabil. (2014) 29:498506. doi: 10.1097/HTR.0000000000000001

24. Ryan NP, Hughes N, Godfrey C, Rosema S, Catroppa C, Anderson VA. Prevalence and predictors of externalizing behavior in young adult survivors of pediatric traumatic brain injury. J. Head Trauma Rehabil. (2015) 30:75-85. doi: 10.1097/HTR.0000000000000123

25. Tsai MC, Tsai KJ, Wang HK, Sung PS, Wu MH, et al. Mood disorders after traumatic brain injury in adolescents and young adults: a nationwide population-based cohort study. J. Pediatr. (2014) 164:136-41.e1. doi: 10.1016/j.jpeds.2013.08.042

26. Adelson PD, Fellows-Mayle W, Kochanek PM, Dixon CE. Morris water maze function and histologic characterization of two age-at-injury experimental models of controlled cortical impact in the immature rat. Childs Nerv. Syst. (2013) 29:43-53. doi: 10.1007/s00381-012-1932-4
27. Adelson PD, Jenkins LW, Hamilton RL, Robichaud P, Tran MP, Kochanek PM. Histopathologic response of the immature rat to diffuse traumatic brain injury. J. Neurotrauma. (2001) 18:967-76. doi: 10.1089/08977150152693674

28. Geddes RI, Peterson BL, Stein DG, Sayeed I. Progesterone treatment shows benefit in female rats in a pediatric model of controlled cortical impact injury. PLoS ONE. (2016) 11:e0146419. doi: 10.1371/journal.pone.0146419

29. Geddes RI, Sribnick EA, Sayeed I, Stein DG. Progesterone treatment shows benefit in a pediatric model of moderate to severe bilateral brain injury. PLoS ONE. (2014) 9:e87252. doi: 10.1371/journal.pone.0087252

30. Newell EA, Todd BP, Luo Z, Evans LP, Ferguson PJ, Bassuk AG. A mouse model for juvenile, lateral fluid percussion brain injury reveals sex-dependent differences in neuroinflammation and functional recovery. J. Neurotrauma. (2020) 37:635-46. doi: 10.1089/neu.2019.6675

31. Raghupathi R, Huh JW. Diffuse brain injury in the immature rat: evidence for an age-at-injury effect on cognitive function and histopathologic damage. J. Neurotrauma. (2007) 24:1596-608. doi: 10.1089/neu.2007.3790

32. Uysal N, Baykara B, Kiray M, Cetin F, Aksu I, et al. Combined treatment with progesterone and magnesium sulfate positively affects traumatic brain injury in immature rats. Turk. Neurosurg. (2013) 23:129-37. doi: 10.5137/1019-5149.JTN.5582-11.1

33. Wang G, Zhang YP, Gao Z, Shields LBE, Li F, et al. Pathophysiological and behavioral deficits in developing mice following rotational acceleration-deceleration traumatic brain injury. Dis. Model Mech. (2018) 11:dmm030387. doi: 10.1242/dmm.030387

34. Huh JW, Widing AG, Raghupathi R. Midline brain injury in the immature rat induces sustained cognitive deficits, bihemispheric axonal injury and neurodegeneration. Exp. Neurol. (2008) 213:84-92. doi: 10.1016/j.expneurol.2008.05.009

35. Baykara B, Aksu I, Buyuk E, Kiray M, Sisman AR, et al. Progesterone treatment decreases traumatic brain injury induced anxiety and is correlated with increased serum IGF-1 levels; prefrontal cortex, amygdala, hippocampus neuron density; and reduced serum corticosterone levels in immature rats. Biotech. Histochem. (2013) 88:250-7. doi: 10.3109/10520295.2013.769630

36. Semple BD, Canchola SA, Noble-Haeusslein LJ. Deficits in social behavior emerge during development after pediatric traumatic brain injury in mice. J. Neurotrauma. (2012) 29:2672-83. doi: 10.1089/neu.2012.2595

37. Kannan N, Ramaiah R, Vavilala MS. Pediatric neurotrauma. Int. J. Crit. Illn. Inj. Sci. (2014) 4:131-7. doi: 10.4103/2229-5151.134152

38. Beauchamp MH, Ditchfield M, Maller JJ, Catroppa C, Godfrey C, et al. Hippocampus, amygdala and global brain changes 10 years after childhood traumatic brain injury. Int. J. Dev. Neurosci. (2011) 29:137-43. doi: 10.1016/j.ijdevneu.2010.12.003

39. DeMaster D, Johnson C, Juranek J, Ewing-Cobbs L. Memory and the hippocampal formation following pediatric traumatic brain injury. Brain Behav. (2017) 7:e00832. doi: 10.1002/brb3.832

40. Dennis EL, Hua X, Villalon-Reina J, Moran LM, Kernan C, et al. Tensor-based morphometry reveals volumetric deficits in moderate $=$ severe pediatric traumatic brain injury. J. Neurotrauma. (2016) 33:840-52. doi: 10.1089/neu.2015.4012

41. Nasr IW, Chun Y, Kannan S. Neuroimmune responses in the developing brain following traumatic brain injury. Exp. Neurol. (2019) 320:112957. doi: 10.1016/j.expneurol.2019.112957

42. Bell MJ, Kochanek PM, Doughty LA, Carcillo JA, Adelson PD, et al. Interleukin-6 and interleukin-10 in cerebrospinal fluid after severe traumatic brain injury in children. J. Neurotrauma. (1997) 14:451-7. doi: 10.1089/neu.1997.14.451

43. Chiaretti A, Genovese O, Aloe L, Antonelli A, Piastra M, et al. Interleukin lbeta and interleukin 6 relationship with paediatric head trauma severity and outcome. Childs Nerv. Syst. (2005) 21:185-93. doi: $10.1007 / \mathrm{s} 00381-004-1032-1$

44. Li N, Yang Y, Glover DP, Zhang J, Saraswati M, et al. Evidence for impaired plasticity after traumatic brain injury in the developing brain. J. Neurotrauma. (2014) 31:395-403. doi: 10.1089/neu.2013.3059

45. Li HX, Feng X, Wang Q, Dong X, Yu M, Tu WJ. Diffusion tensor imaging assesses white matter injury in neonates with hypoxicischemic encephalopathy. Neural. Regen. Res. (2017) 12:603-9. doi: $10.4103 / 1673-5374.205102$ 
46. Dileonardi AM, Huh JW, Raghupathi R. Differential effects of FK506 on structural and functional axonal deficits after diffuse brain injury in the immature rat. J. Neuropathol. Exp. Neurol. (2012) 71:959-72. doi: 10.1097/NEN.0b013e31826f5876

47. Hanlon LA, Raghupathi R, Huh JW. Differential effects of minocycline on microglial activation and neurodegeneration following closed head injury in the neonate rat. Exp. Neurol. (2017) 290:1-14. doi: 10.1016/j.expneurol.2016.12.010

48. Casella EM, Thomas TC, Vanino DL, Fellows-Mayle W, Lifshitz J, et al. Traumatic brain injury alters long-term hippocampal neuron morphology in juvenile, but not immature, rats. Childs Nerv. Syst. (2014) 30:1333-42. doi: 10.1007/s00381-014-2446-z

49. White ER, Pinar C, Bostrom CA, Meconi A, Christie BR. Mild traumatic brain injury produces long-lasting deficits in synaptic plasticity in the female juvenile hippocampus. J. Neurotrauma. (2017) 34:1111-23. doi: $10.1089 /$ neu. 2016.4638

50. Hanlon LA, Raghupathi R, Huh JW. Depletion of microglia immediately following traumatic brain injury in the pediatric rat: implications for cellular and behavioral pathology. Exp. Neurol. (2019) 316:39-51. doi: 10.1016/j.expneurol.2019.04.004

51. Niimi Y, Levison SW. Pediatric brain repair from endogenous neural stem cells of the subventricular zone. Pediatr. Res. (2018) 83:385-96. doi: $10.1038 /$ pr.2017.261

52. Goodus MT, Guzman AM, Calderon F, Jiang Y, Levison SW. Neural stem cells in the immature, but not the mature, subventricular zone respond robustly to traumatic brain injury. Dev. Neurosci. (2015) 37:29-42. doi: $10.1159 / 000367784$

53. Alagappan D, Lazzarino DA, Felling RJ, Balan M, Kotenko SV, Levison SW. Brain injury expands the numbers of neural stem cells and progenitors in the SVZ by enhancing their responsiveness to EGF. ASN Neuro. (2009) 1:AN20090002. doi: 10.1042/AN20090002

54. Felling RJ, Snyder MJ, Romanko MJ, Rothstein RP, Ziegler AN, et al. Neural stem/progenitor cells participate in the regenerative response to perinatal hypoxia/ischemia. J. Neurosci. (2006) 26:4359-69. doi: 10.1523/JNEUROSCI.1898-05.2006

55. Yang Z, Levison SW. Hypoxia/ischemia expands the regenerative capacity of progenitors in the perinatal subventricular zone. Neuroscience. (2006) 139:555-64. doi: 10.1016/j.neuroscience.2005.12.059

56. Levison SW, Rothstein RP, Romanko MJ, Snyder MJ, Meyers RL, Vannucci SJ. Hypoxia/ischemia depletes the rat perinatal subventricular zone of oligodendrocyte progenitors and neural stem cells. Dev. Neurosci. (2001) 23:234-47. doi: 10.1159/000046149

57. Abdelmawgoud H, Saleh A. Anti-inflammatory and antioxidant effects of mesenchymal and hematopoietic stem cells in a rheumatoid arthritis rat model. Adv. Clin. Exp. Med. (2018) 27:873-80. doi: 10.17219/acem/73720

58. Brazel CY, Rosti III RT, Boyce S, Rothstein RP, Levison SW. Perinatal hypoxia/ischemia damages and depletes progenitors from the mouse subventricular zone. Dev. Neurosci. (2004) 26:266-74. doi: $10.1159 / 000082143$

59. Buono KD, Goodus MT, Guardia Clausi M, Jiang Y, Loporchio D, Levison SW. Mechanisms of mouse neural precursor expansion after neonatal hypoxia-ischemia. J. Neurosci. (2015) 35:8855-65. doi: 10.1523/JNEUROSCI.2868-12.2015

60. Romanko MJ, Rothstein RP, Levison SW. Neural stem cells in the subventricular zone are resilient to hypoxia/ischemia whereas progenitors are vulnerable. J. Cereb. Blood Flow Metab. (2004) 24:814-25. doi: 10.1097/01.WCB.0000123906.17746.00

61. Zhang Z, Ishrat S, O'Bryan M, Klein B, Saraswati M, et al. Pediatric traumatic brain injury causes long-term deficits in adult hippocampal neurogenesis and cognition. J. Neurotrauma. (2020) 37:1656-67. doi: 10.1089/neu.2019.6894

62. Clausi MG, Kumari E, Levison SW. Unmasking the responses of the stem cells and progenitors in the subventricular zone after neonatal and pediatric brain injuries. Neural. Regen. Res. (2016) 11:45-8. doi: 10.4103/1673-5374.175041

63. Ong J, Plane JM, Parent JM, Silverstein FS. Hypoxicischemic injury stimulates subventricular zone proliferation and neurogenesis in the neonatal rat. Pediatr. Res. (2005) 58:600-6. doi: 10.1203/01.PDR.0000179381.86809.02
64. Yang Z, You Y, Levison SW. Neonatal hypoxic/ischemic brain injury induces production of calretinin-expressing interneurons in the striatum. J. Comp. Neurol. (2008) 511:19-33. doi: 10.1002/cne.21819

65. Zaidi AU, Bessert DA, Ong JE, Xu H, Barks JD, et al. New oligodendrocytes are generated after neonatal hypoxic-ischemic brain injury in rodents. Glia. (2004) 46:380-90. doi: 10.1002/glia.20013

66. Pendleton JC, Shamblott MJ, Gary DS, Belegu V, Hurtado A, et al. Chondroitin sulfate proteoglycans inhibit oligodendrocyte myelination through PTPsigma. Exp. Neurol. (2013) 247:113-21. doi: 10.1016/j.expneurol.2013.04.003

67. Borlongan CV, Glover LE, Tajiri N, Kaneko Y, Freeman TB. The great migration of bone marrow-derived stem cells toward the ischemic brain: therapeutic implications for stroke and other neurological disorders. Prog. Neurobiol. (2011) 95:213-28. doi: 10.1016/j.pneurobio.2011.08.005

68. Mashkouri S, Crowley MG, Liska MG, Corey S, Borlongan CV. Utilizing pharmacotherapy and mesenchymal stem cell therapy to reduce inflammation following traumatic brain injury. Neural. Regen. Res. (2016) 11:1379-84. doi: 10.4103/1673-5374.191197

69. Parry SM, Peeples ES. The impact of hypoxic-ischemic brain injury on stem cell mobilization, migration, adhesion, and proliferation. Neural. Regen. Res. (2018) 13:1125-35. doi: 10.4103/1673-5374.235012

70. Mori M, Matsubara K, Matsubara Y, Uchikura Y, Hashimoto H, et al. Stromal cell-derived factor-1alpha plays a crucial role based on neuroprotective role in neonatal brain injury in rats. Int. J. Mol. Sci. (2015) 16:18018-32. doi: 10.3390/ijms160818018

71. Miller JT, Bartley JH, Wimborne HJ, Walker AL, Hess DC, et al. The neuroblast and angioblast chemotaxic factor SDF-1 (CXCL12) expression is briefly up regulated by reactive astrocytes in brain following neonatal hypoxic-ischemic injury. BMC Neurosci. (2005) 6:63. doi: 10.1186/1471-2202-6-63

72. Sun L, Lee J, Fine HA. Neuronally expressed stem cell factor induces neural stem cell migration to areas of brain injury. J. Clin. Invest. (2004) 113:1364-74. doi: 10.1172/JCI200420001

73. Yu TS, Kim A, Kernie SG. Donepezil rescues spatial learning and memory deficits following traumatic brain injury independent of its effects on neurogenesis. PLoS ONE. (2015) 10:e0118793. doi: 10.1371/journal.pone. 0118793

74. Gao J, Grill RJ, Dunn TJ, Bedi S, Labastida JA, et al. Human neural stem cell transplantation-mediated alteration of microglial/macrophage phenotypes after traumatic brain injury. Cell Transplant. (2016) 25:1863-77. doi: 10.3727/096368916X691150

75. Disdier C, Stonestreet BS. Hypoxic-ischemic-related cerebrovascular changes and potential therapeutic strategies in the neonatal brain. J. Neurosci. Res. (2020) 98:1468-84. doi: 10.1002/jnr.24590

76. de la Pena I, Sanberg PR, Acosta S, Lin SZ, Borlongan CV. Umbilical cord blood cell and granulocyte-colony stimulating factor: combination therapy for traumatic brain injury. Regen. Med. (2014) 9:409-12. doi: $10.2217 /$ rme.14.32

77. Yasuhara T, Kawauchi S, Kin K, Morimoto J, Kameda M, et al. Cell therapy for central nervous system disorders: current obstacles to progress. CNS Neurosci. Ther. (2020) 26:595-602. doi: 10.1111/cns.13247

78. Harting MT, Jimenez F, Xue H, Fischer UM, Baumgartner J, et al. Intravenous mesenchymal stem cell therapy for traumatic brain injury. J. Neurosurg. (2009) 110:1189-97. doi: 10.3171/2008.9.JNS08158

79. Wang L, Jiang F, Li Q, He X, Ma J. Mild hypothermia combined with neural stem cell transplantation for hypoxic-ischemic encephalopathy: neuroprotective effects of combined therapy. Neural. Regen. Res. (2014) 9:1745-52. doi: 10.4103/1673-5374.143417

80. Ye Q, Wu Y, Wu J, Zou S, Al-Zaazaai AA, et al. Neural stem cells expressing bfgf reduce brain damage and restore sensorimotor function after neonatal hypoxia-ischemia. Cell Physiol. Biochem. (2018) 45:108-18. doi: $10.1159 / 000486226$

81. Kang HC, Kim DS, Kim JY, Kim HS, Lim BY, et al. Behavioral improvement after transplantation of neural precursors derived from embryonic stem cells into the globally ischemic brain of adolescent rats. Brain Dev. (2010) 32:658-68. doi: 10.1016/j.braindev.2009.09.010

82. Sakai T, Sasaki M, Kataoka-Sasaki Y, Oka S, Nakazaki M, et al. Functional recovery after the systemic administration of mesenchymal stem cells in a rat 
model of neonatal hypoxia-ischemia. J. Neurosurg. Pediatr. (2018) 22:513-22. doi: 10.3171/2018.5.PEDS1845

83. Herz J, Koster C, Reinboth BS, Dzietko M, Hansen W, et al. Interaction between hypothermia and delayed mesenchymal stem cell therapy in neonatal hypoxic-ischemic brain injury. Brain Behav. Immun. (2018) 70:118-30. doi: 10.1016/j.bbi.2018.02.006

84. McDonald CA, Djuliannisaa Z, Petraki M, Paton MCB, Penny TR, et al. Intranasal delivery of mesenchymal stromal cells protects against neonatal hypoxic(-)ischemic brain injury. Int. J. Mol. Sci. (2019) 20:2449. doi: 10.3390/ijms20102449

85. Lu P, Jones LL, Snyder EY, Tuszynski MH. Neural stem cells constitutively secrete neurotrophic factors and promote extensive host axonal growth after spinal cord injury. Exp. Neurol. (2003) 181:115-29. doi: 10.1016/S0014-4886(03)00037-2

86. Fu Y, Karbaat L, Wu L, Leijten J, Both SK, Karperien M. Trophic effects of mesenchymal stem cells in tissue regeneration. Tissue Eng. Part B Rev. (2017) 23:515-28. doi: 10.1089/ten.teb.2016.0365

87. Hofer HR, Tuan RS. Secreted trophic factors of mesenchymal stem cells support neurovascular and musculoskeletal therapies. Stem Cell Res. Ther. (2016) 7:131. doi: 10.1186/s13287-016-0394-0

88. Wagenaar N, de Theije CGM, de Vries LS, Groenendaal F, Benders M, Nijboer CHA. Promoting neuroregeneration after perinatal arterial ischemic stroke: neurotrophic factors and mesenchymal stem cells. Pediatr. Res. (2018) 83:372-84. doi: 10.1038/pr.2017.243

89. Iyer SS, Rojas M. Anti-inflammatory effects of mesenchymal stem cells: novel concept for future therapies. Expert Opin. Biol. Ther. (2008) 8:569-81. doi: 10.1517/14712598.8.5.569

90. Wei Y, Xie Z, Bi J, Zhu Z. Anti-inflammatory effects of bone marrow mesenchymal stem cells on mice with Alzheimer's disease. Exp. Ther. Med. (2018) 16:5015-20. doi: 10.3892/etm.2018.6857

91. Sweda R, Phillips AW, Marx J, Johnston MV, Wilson MA, Fatemi A. Glialrestricted precursors protect neonatal brain slices from hypoxic-ischemic cell death without direct tissue contact. Stem Cells Dev. (2016) 25:975-85. doi: $10.1089 /$ scd.2015.0378

92. Ding H, Zhang H, Ding H, Li D, Yi X, et al. Transplantation of placentaderived mesenchymal stem cells reduces hypoxic-ischemic brain damage in rats by ameliorating the inflammatory response. Cell Mol. Immunol. (2017) 14:693-701. doi: 10.1038/cmi.2015.99

93. Zheng Z, Zhang L, Qu Y, Xiao G, Li S, et al. Mesenchymal stem cells protect against hypoxia-ischemia brain damage by enhancing autophagy through brain derived neurotrophic factor/mammalin target of rapamycin signaling pathway. Stem Cells. (2018) 36:1109-21. doi: 10.1002/stem.2808

94. Ahn SY, Chang YS, Sung DK, Sung SI, Yoo HS, et al. Mesenchymal stem cells prevent hydrocephalus after severe intraventricular hemorrhage. Stroke. (2013) 44:497-504. doi: 10.1161/STROKEAHA.112.679092

95. Morioka C, Komaki M, Taki A, Honda I, Yokoyama N, et al. Neuroprotective effects of human umbilical cord-derived mesenchymal stem cells on periventricular leukomalacia-like brain injury in neonatal rats. Inflamm. Regen. (2017) 37:1. doi: 10.1186/s41232-016-0032-3

96. Wei ZZ, Lee JH, Zhang Y, Zhu YB, Deveau TC, et al. Intracranial transplantation of hypoxia-preconditioned iPSC-derived neural progenitor cells alleviates neuropsychiatric defects after traumatic brain injury in juvenile rats. Cell Transplant. (2016) 25:797-809. doi: $10.3727 / 096368916$ X690403

97. Chen A, Siow B, Blamire AM, Lako M, Clowry GJ. Transplantation of magnetically labeled mesenchymal stem cells in a model of perinatal brain injury. Stem Cell Res. (2010) 5:255-66. doi: 10.1016/j.scr.2010.08.004

98. Li L, Chopp M, Ding G, Davoodi-Bojd E, Li Q, et al. Diffuse white matter response in trauma-injured brain to bone marrow stromal cell treatment detected by diffusional kurtosis imaging. Brain Res. (2019) 1717:127-35. doi: 10.1016/j.brainres.2019.04.020

99. Zhu LH, Bai X, Zhang N, Wang SY, Li W, Jiang L. Improvement of human umbilical cord mesenchymal stem cell transplantation on glial cell and behavioral function in a neonatal model of periventricular white matter damage. Brain Res. (2014) 1563:13-21. doi: 10.1016/j.brainres.2014.03.030

100. Vaes JEG, Vink MA, de Theije CGM, Hoebeek FE, Benders M, Nijboer CHA. The potential of stem cell therapy to repair white matter injury in preterm infants: lessons learned from experimental models. Front. Physiol. (2019) 10:540. doi: 10.3389/fphys.2019.00540

101. Lee YC, Chang YC, Wu CC, Huang CC. Hypoxia-preconditioned human umbilical vein endothelial cells protect against neurovascular damage after hypoxic ischemia in neonatal brain. Mol. Neurobiol. (2018) 55:7743-57. doi: 10.1007/s12035-018-0867-5

102. Wu CC, Chen YC, Chang YC, Wang LW, Lin YC, et al. Human umbilical vein endothelial cells protect against hypoxic-ischemic damage in neonatal brain via stromal cell-derived factor 1/C-X-C chemokine receptor type 4. Stroke. (2013) 44:1402-9. doi: 10.1161/STROKEAHA.111.000719

103. Yu Y, Yan Y, Luo Z, Luo P, Xiao N, et al. Effects of human umbilical cord blood $\mathrm{CD} 34(+)$ cell transplantation in neonatal hypoxic-ischemia rat model. Brain Dev. (2019) 41:173-81. doi: 10.1016/j.braindev.2018.08.007

104. Baburamani AA, Ek CJ, Walker DW, Castillo-Melendez M. Vulnerability of the developing brain to hypoxic-ischemic damage: contribution of the cerebral vasculature to injury and repair? Front. Physiol. (2012) 3:424. doi: 10.3389/fphys.2012.00424

105. Acosta SA, Tajiri N, Shinozuka K, Ishikawa H, Sanberg PR, et al. Combination therapy of human umbilical cord blood cells and granulocyte colony stimulating factor reduces histopathological and motor impairments in an experimental model of chronic traumatic brain injury. PLOS ONE. (2014) 9:e90953. doi: 10.1371/journal.pone.0090953

106. Bilen S, Pinarli F, Ak F, Fadillioglu E, Albayrak A, et al. Treatment efficacy with bone marrow derived mesenchymal stem cells and minocycline in rats after cerebral ischemic injury. Stem Cell Rev. Rep. (2013) 9:219-25. doi: 10.1007/s12015-012-9422-3

107. Hanlon LA, Huh JW, Raghupathi R. Minocycline transiently reduces microglia/macrophage activation but exacerbates cognitive deficits following repetitive traumatic brain injury in the neonatal rat. J. Neuropathol. Exp. Neurol. (2016) 75:214-26. doi: 10.1093/jnen/nlv021

108. Pena I, Borlongan CV. Translating G-CSF as an adjunct therapy to stem cell transplantation for stroke. Transl. Stroke Res. (2015) 6:421-9. doi: 10.1007/s12975-015-0430-x

109. Yata K, Matchett GA, Tsubokawa T, Tang J, Kanamaru K, Zhang JH. Granulocyte-colony stimulating factor inhibits apoptotic neuron loss after neonatal hypoxia-ischemia in rats. Brain Res. (2007) 1145:227-38. doi: 10.1016/j.brainres.2007.01.144

110. Yang YN, Lin CS, Yang CH, Lai YH, Wu PL, Yang SN. Neurogenesis recovery induced by granulocyte-colony stimulating factor in neonatal rat brain after perinatal hypoxia. Pediatr. Neonatol. (2013) 54:380-8. doi: 10.1016/j.pedneo.2013.04.011

111. Doycheva D, Shih G, Chen H, Applegate R, Zhang JH, Tang J. Granulocytecolony stimulating factor in combination with stem cell factor confers greater neuroprotection after hypoxic-ischemic brain damage in the neonatal rats than a solitary treatment. Transl. Stroke Res. (2013) 4:171-8. doi: $10.1007 / \mathrm{s} 12975-012-0225-2$

112. Davidson JO, Wassink G, van den Heuij LG, Bennet L, Gunn AJ. Therapeutic hypothermia for neonatal hypoxic-ischemic encephalopathy - where to from here? Front. Neurol. (2015) 6:198. doi: 10.3389/fneur.2015.00198

113. Park WS, Sung SI, Ahn SY, Yoo HS, Sung DK, et al. Hypothermia augments neuroprotective activity of mesenchymal stem cells for neonatal hypoxic-ischemic encephalopathy. PLoS ONE. (2015) 10:e0120893. doi: 10.1371/journal.pone. 0120893

114. Lee JH, Yoon YM, Lee SH. Hypoxic preconditioning promotes the bioactivities of mesenchymal stem cells via the HIF-1alpha-GRP78-Akt axis. Int. J. Mol. Sci. (2017) 18:1320. doi: 10.3390/ijms 18061320

115. Wei ZZ, Zhu YB, Zhang JY, McCrary MR, Wang S, et al. Priming of the cells: hypoxic preconditioning for stem cell therapy. Chin. Med. J. (2017) 130:2361-74. doi: 10.4103/0366-6999.215324

116. Ara J, De Montpellier S. Hypoxic-preconditioning enhances the regenerative capacity of neural stem/progenitors in subventricular zone of newborn piglet brain. Stem Cell Res. (2013) 11:669-86. doi: 10.1016/j.scr.2013.04.007

117. van Velthoven CT, Sheldon RA, Kavelaars A, Derugin N, Vexler ZS, et al. Mesenchymal stem cell transplantation attenuates brain injury after neonatal stroke. Stroke. (2013) 44:1426-32. doi: 10.1161/STROKEAHA.111.000326

118. Zhao F, Qu Y, Liu H, Du B, Mu D. Umbilical cord blood mesenchymal stem cells co-modified by TERT and BDNF: a novel neuroprotective therapy 
for neonatal hypoxic-ischemic brain damage. Int. J. Dev. Neurosci. (2014) 38:147-54. doi: 10.1016/j.ijdevneu.2014.06.014

119. Fletcher JL, Wood RJ, Nguyen J, Norman EML, Jun CMK, et al. Targeting TrkB with a brain-derived neurotrophic factor mimetic promotes myelin repair in the brain. J. Neurosci. (2018) 38:7088-99. doi: 10.1523/JNEUROSCI.0487-18.2018

120. Nguyen HTH, Wood RJ, Prawdiuk AR, Furness SGB, Xiao J, et al. TrkB Agonist LM22A-4 increases oligodendroglial populations during myelin repair in the corpus callosum. Front. Mol. Neurosci. (2019) 12:205. doi: 10.3389/fnmol.2019.00205

121. Vakhshiteh F, Atyabi F, Ostad SN. Mesenchymal stem cell exosomes: a two-edged sword in cancer therapy. Int. J. Nanomed. (2019) 14:2847-59. doi: 10.2147/IJN.S200036

122. Williams AM, Dennahy IS, Bhatti UF, Halaweish I, Xiong Y, et al. Mesenchymal stem cell-derived exosomes provide neuroprotection and improve long-term neurologic outcomes in a swine model of traumatic brain injury and hemorrhagic shock. J. Neurotrauma. (2019) 36:54-60. doi: $10.1089 /$ neu.2018.5711

123. Ni H, Yang S, Siaw-Debrah F, Hu J, Wu K, et al. Exosomes derived from bone mesenchymal stem cells ameliorate early inflammatory responses following traumatic brain injury. Front. Neurosci. (2019) 13:14. doi: 10.3389/fnins.2019.00014

124. Patel NA, Moss LD, Lee JY, Tajiri N, Acosta S, et al. Long noncoding RNA MALAT1 in exosomes drives regenerative function and modulates inflammation-linked networks following traumatic brain injury. J. Neuroinflammation. (2018) 15:204. doi: 10.1186/s12974-018-1240-3

125. Thomi G, Joerger-Messerli M, Haesler V, Muri L, Surbek D, Schoeberlein A. Intranasally administered exosomes from umbilical cord stem cells have preventive neuroprotective effects and contribute to functional recovery after perinatal brain injury. Cells. (2019) 8:855. doi: 10.3390/cells8080855

126. Thomi G, Surbek D, Haesler V, Joerger-Messerli M, Schoeberlein A. Exosomes derived from umbilical cord mesenchymal stem cells reduce microglia-mediated neuroinflammation in perinatal brain injury. Stem Cell Res. Ther. (2019) 10:105. doi: 10.1186/s13287-019-1207-z

127. Ophelders DR, Wolfs TG, Jellema RK, Zwanenburg A, Andriessen P, et al. Mesenchymal stromal cell-derived extracellular vesicles protect the fetal brain after hypoxia-ischemia. Stem Cells Transl. Med. (2016) 5:754-63. doi: 10.5966/sctm.2015-0197
128. Billiards SS, Haynes RL, Folkerth RD, Trachtenberg FL, Liu LG, et al. Development of microglia in the cerebral white matter of the human fetus and infant. J. Comp. Neurol. (2006) 497:199-208. doi: 10.1002/cne.20991

129. Kaur C, Rathnasamy G, Ling EA. Biology of microglia in the developing brain. J. Neuropathol. Exp. Neurol. (2017) 76:736-53. doi: 10.1093/jnen/nlx056

130. Robertson CL, Fidan E, Stanley RM, Noje C, Bayir H. Progesterone for neuroprotection in pediatric traumatic brain injury. Pediatr. Crit. Care Med. (2015) 16:236-44. doi: 10.1097/PCC.0000000000000323

131. Cannella LA, McGary H, Ramirez SH. Brain interrupted: early life traumatic brain injury and addiction vulnerability. Exp. Neurol. (2019) 317:191-201. doi: 10.1016/j.expneurol.2019.03.003

132. Eyolfson E, Khan A, Mychasiuk R, Lohman AW. Microglia dynamics in adolescent traumatic brain injury. J. Neuroinflammation. (2020) 17:326. doi: 10.1186/s12974-020-01994-Z

133. Mychasiuk R, Hehar H, Ma I, Kolb B, Esser MJ. The development of lasting impairments: a mild pediatric brain injury alters gene expression, dendritic morphology, and synaptic connectivity in the prefrontal cortex of rats. Neuroscience. (2015) 288:145-55. doi: 10.1016/j.neuroscience.2014.12.034

134. Ewing-Cobbs L, Prasad MR, Cox CSJr, Granger DA, Duque G, Swank PR. Altered stress system reactivity after pediatric injury: Relation with post-traumatic stress symptoms. Psychoneuroendocrinology. (2017) 84:6675. doi: 10.1016/j.psyneuen.2017.06.003

135. Conrad CD. Chronic stress-induced hippocampal vulnerability: the glucocorticoid vulnerability hypothesis. Rev. Neurosci. (2008) 19:395-411. doi: 10.1515/REVNEURO.2008.19.6.395

Conflict of Interest: The authors declare that the research was conducted in the absence of any commercial or financial relationships that could be construed as a potential conflict of interest.

Copyright (C) 2020 Lengel, Sevilla, Romm, Huh and Raghupathi. This is an openaccess article distributed under the terms of the Creative Commons Attribution License (CC BY). The use, distribution or reproduction in other forums is permitted, provided the original author(s) and the copyright owner(s) are credited and that the original publication in this journal is cited, in accordance with accepted academic practice. No use, distribution or reproduction is permitted which does not comply with these terms. 